\title{
Association of cytosolic sialidase Neu2 with plasma membrane enhances Fas-mediated apoptosis by impairing PI3K-Akt/mTOR- mediated pathway in pancreatic cancer cells
}

\author{
Shalini Nath ${ }^{1}$, Chhabinath Mandal ${ }^{2}$, Uttara Chatterjee ${ }^{3}$ and Chitra Mandal ${ }^{1}$
}

\begin{abstract}
Modulation of sialylation by sialyltransferases and sialidases plays essential role in carcinogenesis. There are few reports on sialyltransferase, however, the contribution of cytosolic sialidase (Neu2) remains unexplored in pancreatic ductal adenocarcinoma (PDAC). We observed lower expression of Neu2 in different PDAC cells, patient tissues, and a significant strong association with clinicopathological characteristics. Neu2 overexpression guided drug-resistant MIAPaCa2 and AsPC1 cells toward apoptosis as evidenced by decreased Bcl2/Bax ratio, activation of caspase-3/caspase-6/caspase-8, PARP reduction, reduced CDK2/CDK4/CDK6, and cyclin-B1/cyclin-E with unaffected caspase-9. Neu2-overexpressed cells exhibited higher expression of Fas/CD95-death receptor, FasL, FADD, and Bid cleavage confirming extrinsic pathway-mediated apoptosis. a2,6-linked sialylation of Fas helps cancer cells to survive, which is a substrate for Neu2. Therefore, their removal should enhance Fas-mediated apoptosis. Neu2-overexpressed cells indeed showed increased enzyme activity even on membrane. Interestingly, this membrane-bound Neu2 exhibited enhanced association with Fas causing its desialylation and activation as corroborated by decreased association of Fas with a2,6-sialic acid-binding lectin. Additionally, enhanced cytosolic Neu2 inhibited the expression of several growth factor-mediated signaling molecules involved in PI3K/Akt-mTOR pathway probably through desialylation which in turn also causes Fas activation. Furthermore, Neu2-overexpressed cells exhibited reduced cell migration, invasion with decreased VEGF, VEGFR, and MMP9 levels. To the best of our knowledge, this is the first report of cytosolic Neu2 on membrane, its association with Fas, enhanced desialylation, activation, and Fasmediated apoptosis. Taken together, our study ascertains a novel concept by which the function of Fas/CD95 could be modulated indicating a critical role of upstream Neu2 as a promising target for inducing apoptosis in pancreatic cancer.
\end{abstract}

\section{Introduction}

More than $90 \%$ of pancreatic cancers are pancreatic ductal adenocarcinoma (PDAC), is fatal due to poor

\footnotetext{
Correspondence: Chitra Mandal (chitra_mandal@yahoo.com)

${ }^{1}$ Cancer Biology and Inflammatory Disorder Division, Council of Scientific and Industrial Research (CSIR), Indian Institute of Chemical Biology (IICB), 4, Raja S.C. Mullick Road, Jadavpur, Kolkata 700032 West Bengal, India

${ }^{2}$ National Institute of Pharmaceutical Education and Research, IICB, CSIR, Kolkata 700032 West Bengal, India

Full list of author information is available at the end of the article

Edited by A. Stephanou
}

diagnosis and prognosis ${ }^{1,2}$. Because of its rapid progression, invasiveness, and drug resistance, most have metastatic cancers ${ }^{3-6}$. The multifaceted biological mechanisms remain mostly unknown.

Abnormal glycosylation and fucosylation are common features in cancers ${ }^{7-11}$. Hence these alterations play a significant role in modulating differentiation, signaling, adhesion, invasiveness, metastasis, and apoptosis ${ }^{12}$. Pancreatic cancer cells exhibited higher $\alpha 2,3$ - and $\alpha 2,6$-linked me. The images or other third party material in this article are included in the article's Creative Commons license, unless indicated otherwise in a credit line to the material. material is not included in the article's Creative Commons license and your intended use is not permitted by statutory regulation or exceeds the permitted use, you will need to obtain permission directly from the copyright holder. To view a copy of this license, visit http://creativecommons.org/licenses/by/4.0/. 
sialic acids (SAs) which mainly affects its higher rate of metastasis $^{13,14}$.

Enhanced SAs depend on the balance of SA-modulatory enzymes sialyltransferases and sialidases ${ }^{15-17}$. Elevated levels of the sialyltransferases are common in cancers including PDAC ${ }^{18-25}$. Mammalian cells have four sialidases namely lysosomal (Neu1), cytosolic (Neu2), membrane bound (Neu3), and luminal (Neu4) differing in their enzymatic property and substrate specificity. They are important for the balance of sialylation and behave differently during carcinogenesis ${ }^{26,27}$.

Neu2 expression is either very low or undetectable in normal human tissue with the exception of prostate cancer and myoblast ${ }^{28-30}$. Neu2 is repressed in leukemia, melanoma, and colon adenocarcinoma ${ }^{31-33}$.

Death receptor Fas (CD95) stimulates several signaling cascades for inducing apoptosis. This is commonly disrupted and implicated in tumor cell survival ${ }^{34,35}$. Both $O$ and $N$-linked glycans and $\alpha 2,6$-sialylations of Fas are reported in colon cancer ${ }^{36}$. The substrate specificity of Neu2 is toward glycoproteins/glycolipids and oligosaccharides. However, the functional significance of Neu2 in Fas-mediated apoptosis has received least attention.

PI3K-Akt pathway is upregulated in many cancers ${ }^{37,38}$. Due to its constitutive activation, PDAC exhibited high metastatic potential and chemoresistance. Many of the pathway molecules are altered by sialylation ${ }^{39,40}$. The inhibition of PI3K-Akt pathway sometimes is responsible for the activation of Fas-mediated apoptosis in gastric, colon, and prostate cancer ${ }^{41-43}$. Alterations of sialylation of the PI3K pathway molecules cause inactivation of oncogenes like PI3K/mTOR resulting in regression of cancer. Hence, Neu2 may play an important role in desialylation of such pathway molecules which is not fully understood.

Initially, we observed lower expression of Neu2 in different PDAC cell lines and in patient tissues. Moreover, such reduced Neu2 exhibited a significant strong association with clinicopathological characteristics of these patients (Table 1). Accordingly, we aim to establish the role of this cytosolic sialidase on sialylated Fas in Fasmediated apoptosis in PDAC cell lines with different mutations (Table 2).

Here, we demonstrated that overexpression of cytosolic Neu2 increased enzyme activity on the membrane. Enhanced membrane-bound Neu2 exhibited an increased association with $\alpha 2,6$-linked SAs on Fas causing its desialylation and activation as corroborated by decreased association of Fas with an SA-binding lectin, Sambucus nigra agglutinin (SNA). Such desialylated Fas guided these cells toward enhanced apoptosis through extrinsic pathway. Additionally, enhanced cytosolic Neu2 desialylated several signaling molecules present in PI3K-Akt/mTOR pathway. All these events accelerated apoptosis by inhibiting this pathway which also causes upregulation of Fas expression
Table 1 Association of Neu2 expression with clinicopathological characteristics in patients with pancreatic cancer

\begin{tabular}{|c|c|}
\hline \multicolumn{2}{|l|}{ Gender } \\
\hline Male & 12 \\
\hline Female & 8 \\
\hline Age & $40-85$ \\
\hline \multicolumn{2}{|l|}{ Location of tumor } \\
\hline Head, body & 20 \\
\hline \multicolumn{2}{|l|}{ T category } \\
\hline $\mathrm{T} 1$ & 1 \\
\hline $\mathrm{T} 2$ & 11 \\
\hline $\mathrm{T} 3$ & 8 \\
\hline \multicolumn{2}{|l|}{$\mathrm{N}$ category } \\
\hline No & 11 \\
\hline $\mathrm{N} 1$ & 9 \\
\hline \multicolumn{2}{|l|}{ M category } \\
\hline Mo & 20 \\
\hline M1 & 0 \\
\hline \multicolumn{2}{|l|}{ Surgical procedure } \\
\hline Pancreatoduodenectomy & 20 \\
\hline \multicolumn{2}{|l|}{ Histological differentiation } \\
\hline Well & 3 \\
\hline Moderately & 16 \\
\hline Poorly & 1 \\
\hline Chemotherapy & 0 \\
\hline Adjuvant therapy & 0 \\
\hline \multicolumn{2}{|l|}{ Neu2 expression } \\
\hline Neu2 negative & 17 \\
\hline Neu2 positive & 3 \\
\hline
\end{tabular}

and activation. These entire processes diminished the survival of Neu2-transfected drug-resistant PDAC cells through abridged cell migration and invasiveness.

To the best of our knowledge, this is the first information for the presence of Neu2 on the membrane and establishing a link between the function of cytosolic Neu2 for desialylation of membrane-bound Fas. Neu2, therefore, may be a pivotal upstream molecule in regulating apoptosis.

\section{Results}

Neu2 is downregulated in human pancreatic cancer tissues Initially, we compared the status of Neu1/Neu2/ Neu3/Neu4 in cancer and normal tissue specimens by 


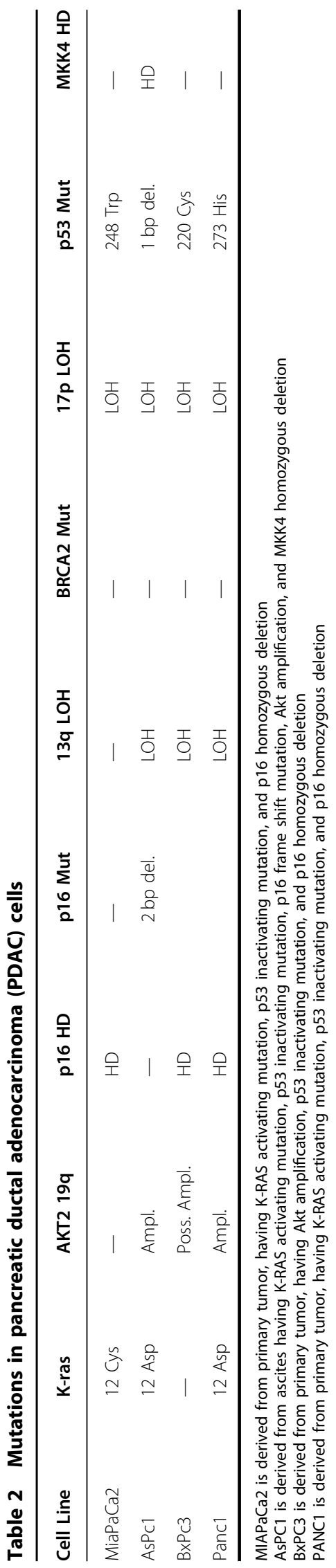

immunohistochemistry. Optical density score conferred higher Neu1, Neu3, and Neu4 positivity in the tumor tissues (Fig. 1a, b). In contrast, statistically significant low or undetectable expression of Neu2 was observed in all tissues from 20 patients compared to 20 normal counterparts (Table 1). Interestingly, we observed a strong association of reduced expression of $\mathrm{Neu} 2$ with clinicopathological characteristics of these patients. This data suggested that the loss of Neu2 possibly helps higher sialylation status in manifestation of this cancer.

Real-time PCR analysis of sialidases in four representatives PDAC cells namely MIAPaCa2, AsPC1, BxPC3, and PANC1 (Table 2) showed reduced Neu2 expression compared to other three sialidases (Fig. 1c). However, MIAPaCa2 and AsPC1 exhibited lowest Neu2 expression amongst them. Interestingly, they also possess different mutations status. Hence, we have selected these two cells for subsequent study. RT-PCR analysis of all these sialidases also showed similar trend in MIAPaCa2 and AsPC1 (Fig. 1d).

Accordingly, Neu2 was transfected in MIAPaCa2 and AsPC1. Neu2-transfected cells exhibited higher mRNA expression of Neu2 than mock both by real time PCR (Fig. 1e) and RT-PCR (Fig. 1f). Western blot analysis also revealed enhanced level of Neu2 protein (Fig. 1g). However, the expression of Neu1, Neu3, and Neu4 remain unchanged in Neu2-overexpressed MIAPaCa2 (Fig. 1h) and AsPC1 (Fig. 1i).

\section{Sialidase activity in Neu2-transfected cells}

We measured the sialidase activity both in cytosolic and membrane fractions of Neu2-transfected cells separately at $\mathrm{pH} 5.5$ toward an artificial substrate MU-NeuAc (Fig. 1j-m). An increased cytosolic enzyme activity was observed in the Neu2-transfected MIAPaCa2 $(0.2414 \pm$ $0.0044 \mu \mathrm{M} / \mathrm{h} / \mathrm{mg}$ protein) compared to mock-transfected $(0.09842 \pm 0.00026 \mu \mathrm{M} / \mathrm{h} / \mathrm{mg}$ protein) cells (Fig. 1j). Similar trend was found in Neu2-transfected AsPC1 $(0.2579 \pm 0.019 \mu \mathrm{M} / \mathrm{h} / \mathrm{mg}$ protein $)$ compared to mock $(0.1048 \pm 0.0266 \mu \mathrm{M} / \mathrm{h} / \mathrm{mg}$ protein) (Fig. 1l).

We also found increased level of sialidase activity on membrane in Neu2-overexpressed MIAPaCa2 (mock = $0.0340 \pm 0.0077$ vs. $\mathrm{Neu} 2=0.07767 \pm 0.0107 \mu \mathrm{M} / \mathrm{h} / \mathrm{mg}$ protein) (Fig. 1k). Neu2-transfected AsPC1 also exhibited similar pattern; mock $=0.04372 \pm 0.0027$ vs. $\mathrm{Neu} 2=$ $0.09933 \pm 0.0108 \mu \mathrm{M} / \mathrm{h} / \mathrm{mg}$ protein (Fig. $1 \mathrm{~m}$ ). Hence it may be concluded that though Neu2 is a cytosolic enzyme, it also exhibited slightly higher sialidase activity in membrane fraction.

\section{Neu2 overexpression inhibits cell proliferation}

Next, we checked the growth potential of MIAPaCa2 and AsPC1 due to enhanced Neu2 activity by 3-(4,5 


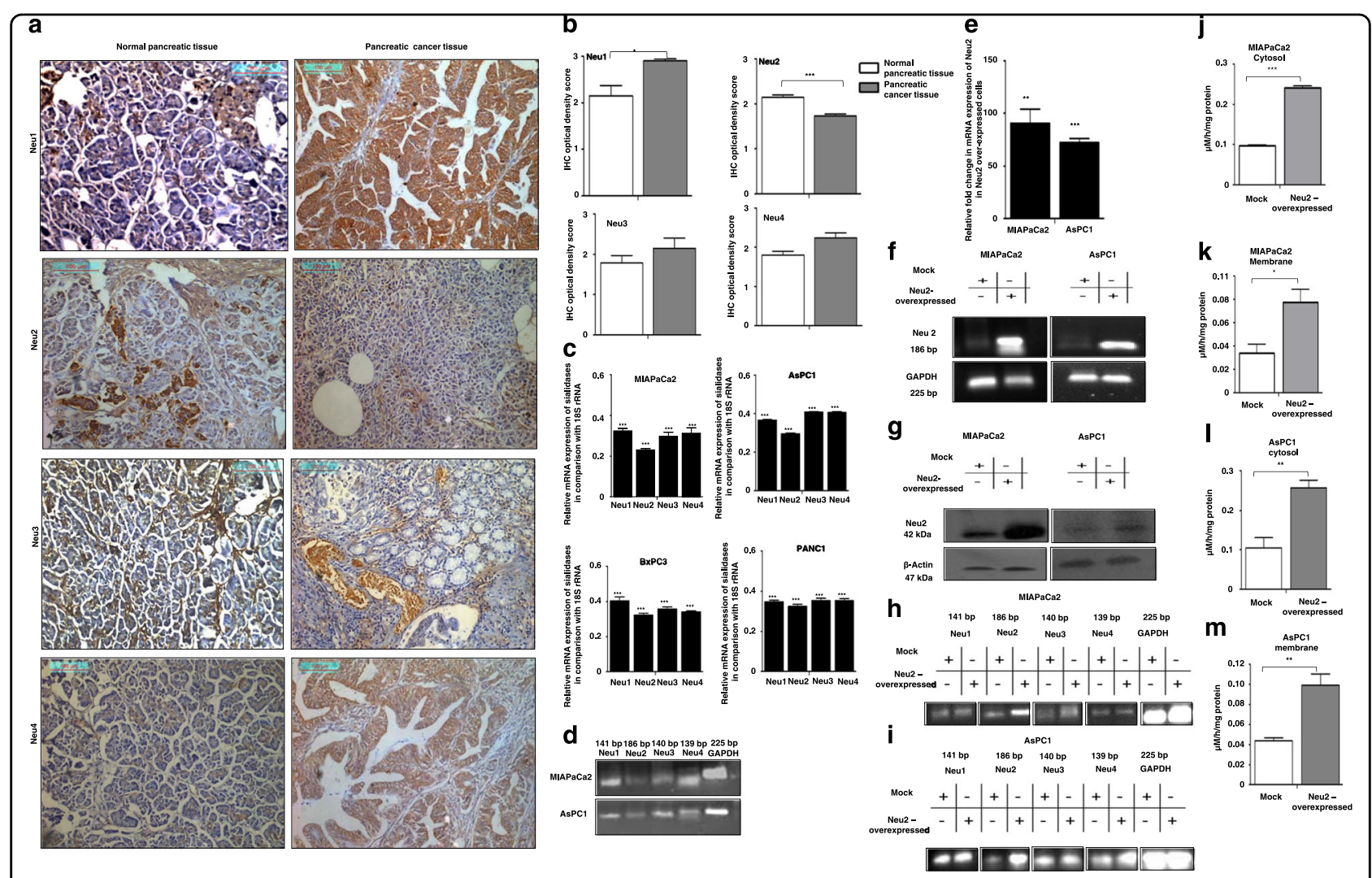

Fig. 1 Neu2 is downregulated among the other mammalian sialidases in human pancreatic carcinomas. a Expression of four different sialidases in patient's tissue compared to normal. Tissue samples from pancreatic tumor and their normal counterpart were collected by our clinical collaborator at the Institute of Postgraduate Medical Education and Research Hospital, Kolkata. The Neu1, Neu2, Neu3, and Neu4 protein levels were detected in human pancreatic cancer and normal tissue specimens by immunohistochemistry using respective antibodies. Representative images of pancreatic adenocarcinoma were taken with $\times 20$ magnification, showing high positivity for Neu1, Neu3, and Neu4 than normal tissue, poorly differentiated adenocarcinoma showing reduced expression of Neu2 than normal tissue. $\mathbf{b}$ Bar graphs represent IHC optical density scores of normal and patients tissue samples for Neu1, Neu2, Neu3, and Neu4 sialidases as measured by ImageJ software. c Genetic expression of four different sialidases in MIAPaCa2, AsPC1, BxPC3, and PANC1 cells. RNA was isolated from MIAPaCa2, AsPC1, BxPC3, and PANC1 cell lines. CDNA was prepared by ImPromll-Reverse transcription system according to manufacturer's protocol. Relative mRNA expression of Neu1, Neu2, Neu3, and Neu4 was evaluated by real-time PCR analysis with specific primers of Neu1, Neu2, Neu3, and Neu4 as described in Table 4. Values are normalized against 185 rRNA expression ( $n=3$ experiments). d Genetic expressions of different sialidases were additionally measured in MIAPaCa2 and AsPC1 cell lines by semi-quantitative RT-PCR. The image was visualized and photographed in Bio-Rad Gel Documentation system. GAPDH was used as loading control. e, $\mathbf{f}$ Enhanced Neu2 expression in Neu2-transfected MIAPaCa2 and AsPC1 cells. MIAPaCa2 and AsPC1 cells were transfected with the mock and PCDNA3.1-Neu2 expression vector. Neu2 expression was measured after transfection. Real time and semi-quantitative RT-PCR analysis were done from total RNA extracted from mock and Neu2-overexpressed cells as described in Material and methods to detect the Neu2 expression with the specific primer. Fold change in mRNA expression of Neu2 by real-time PCR analysis in MIAPaCa2 and AsPC1 relative to that of mock-transfected cells were determined. Values were normalized against $18 \mathrm{~S}$ rRNA expression ( $n=3$ experiments). GAPDH was used as loading control for semi-quantitative RT-PCR. The images were visualized and photographed as described above. $\mathbf{g}$ Higher level of Neu2 protein in Neu2-transfected MIAPaCa2 and AsPC1 cells. Cell lysate from mock and Neu2-overexpressed PDAC cells was used for western blot analysis to determine the status of Neu2 protein. Blots were probed with the antibody against Neu2. $\beta$-actin was used as loading control. $\mathbf{h}$ Genetic expression of different sialidases by RT-PCR in MIAPaCa2 cells after Neu2 overexpression. GAPDH was used as loading control. i Genetic expression of different sialidases by RT-PCR in AsPC1 cells after Neu2 overexpression. GAPDH was used as loading control. $\mathbf{j}$ Enhanced sialidase activity in cytosol of Neu2-overexpressed MIAPaCa2 cells. The enzyme activity of cytosolic protein $(50 \mu \mathrm{g})$ of Neu2-overexpressed MIAPaCa2 cells was measured at pH 5.5 using MU-Neu5Ac as substrate by fluorimetric method with excitation at $365 \mathrm{~nm}$ and emission at $450 \mathrm{~nm}$. Mock-transfected cells were used for comparison. Data were derived from three independent experiments and presented as mean values \pm S.D., significance: ${ }^{* * *} p<0.001$. $\mathbf{k}$ Membrane fractions exhibited higher sialidase activity Neu2-overexpressed MIAPaCa2 cells. Sialidase activity in $100 \mu \mathrm{g}$ of protein of the membrane fractions of Neu2-overexpressed MIAPaCa2 cells was determined at pH 5.5 by fluorimetric method. Data were derived from three independent experiments and presented as mean values \pm S.D., significance: ${ }^{*} p<0.05$. I Enhanced sialidase activity in cytosol of Neu2-overexpressed AsPC1 cells. The enzyme activity in cytosolic protein of Neu2overexpressed AsPC1 cells was measured as described in $\mathbf{j}$. Significance: ${ }^{* *} p=0.0095 . \mathbf{m}$ Membrane fractions exhibited higher sialidase activity Neu2overexpressed AsPC1 cells. Sialidase activity in the membrane fractions of Neu2-overexpressed AsPC1 cells was determined as described in $\mathbf{k}$. Significance: ${ }^{* *} p=0.0076$ 
dimethyl thiazol-2yl)-2,5 diphenyltetrazolium bromide (MTT) assay. The Neu2-transfected cells revealed an impaired proliferation capacity after 3 days of culture in the serum-starved condition which was used as apoptotic stimuli compared to mock. Less number of viable Neu2-overexpressed MIAPaCa2 (Fig. 2a) and AsPC1 (Fig. 2c) cells compared to mock were observed in microscope.The percent of cell viability was significantly reduced by $51.35 \pm 11.74$ and $48.67 \pm 0.78$ in MIAPaCa2 (Fig. 2b) and AsPC1 (Fig. 2d) respectively by MTT.

\section{Neu2-induced apoptosis is confirmed by annexin V/PI}

Since significant cell death was observed in Neu2-transfected cells, we checked the mode of this event after $24 \mathrm{~h}$ serum starvation. Neu2 overexpression caused surface phosphatidylserine externalization in MIAPaCa2. AnnexinV positivity was $10.90 \pm 0.493$ compared to $6.47 \pm 0.203$ in mock-transfected cells illustrating the features of early apoptosis (Fig. 2e). Neu2-transfected AsPC1 also exhibited higher annexin V positivity.

A substantial number $(36.9 \pm 1.429)$ of Neu2transfected MIAPaCa2 lost membrane integrity and showed late apoptotic bodies as evidenced by both annexin $\mathrm{V}$ and PI positivity. AsPC1 also showed a similar trend. Hence it is confirmed that growth inhibition in Neu2-transfected cells was due to apoptosis.

Neu2 overexpression modulates cell cycle-related proteins

To determine whether growth inhibition induced by Neu2 was associated with the regulation of cell cyclerelated proteins, we checked the status of these molecules both in mock and Neu2-transfected cells by immunoblotting (Fig. 2f). Neu2 overexpression upregulated Chk1 and Chk2. Activated Chk1 and Chk2 subsequently led to the reduction of the cyclins and cyclin-dependent kinases. We observed that early G1-cell cycle phase regulatory proteins (CDK4 and CDK6) were downregulated after Neu2 overexpression. Late G1-phase regulatory proteins (cyclin E and CDK2) were also reduced. Additionally, cyclin B1 involved in the transition of G2 to the $\mathrm{M}$ phase was decreased. Modulation of all these proteins suggested that enhanced Neu2 hinders cell growth by impeding different checkpoints, hence it may be stated that as an enzyme it affects the overall cell cycle phases.

\section{Neu2 induces modulation of anti-apoptotic and pro-apoptotic molecules}

We then investigated the probable cause of the observed susceptibility to apoptotic stimuli. We found enhanced mRNA expression of the pro-apoptotic genes (Bax) and effector caspase (caspase 3), but not caspase 9 in
Neu2-overexpressed MIAPaCa2 compared to mocktransfected cells after 24 and $48 \mathrm{~h}$ (Fig. 3a).

We also observed higher mRNA level expression of Bax and Cas3 in both MIAPaCa2 (Fig. 3b) and AsPC1 (Fig. 3c) by real-time PCR analysis after $48 \mathrm{~h}$. However, the lower genetic expressions of caspase 9 were observed in both the cells.

Western blot analysis also showed higher level of Bax in Neu2-transfected MIAPaCa2 ( 6.5 fold) and AsPC1 ( 1.5 fold), whereas caspase 9 remained unchanged, which is a hallmark protein for the intrinsic apoptotic pathway (Fig. 3d).

Consistent with these data, Neu2-transfected MIAPaCa2 and AsPC1 exhibited decreased level of anti-apoptotic proteins, Bcl-2 ( 15.08 and 2.0 fold) respectively. PARP, a DNA-repairing enzyme also reduced in the Neu2transfected cells compared to Mock. Overall, the reduction of Bcl-2 and upregulation of Bax supports the notion of involvement of enhanced $\mathrm{Neu} 2$ in the apoptosisregulating pathways in these transfected cells.

\section{Neu2 induces reduced cell proliferation through extrinsic apoptotic pathway}

Interestingly, we observed a significant increase of activated caspase 6 and caspase 8 which are hallmark proteins for extrinsic apoptosis pathway in Neu2overexpressed MIAPaCa2 and AsPC1 (Fig. 3e). The cross-talk between the cell surface-mediated apoptotic signal and the mitochondria is caused by Bid, and hence its activation is very important. We observed cleavage of Bid along with the enhanced level of FADD. Taken together, these results suggest that caspase- 8 and FADD activation along with cleaved Bid in Neu2-transfected PDAC may be induced by activation of the death receptor-mediated apoptosis.

\section{Enhanced expression of Fas and FasL in Neu2-transfected cells}

Next, we searched for the death receptor mechanism in Neu2-transfected cells. We observed a 1.4 and 1.6-fold upregulation of Fas/CD95 in Neu2-transfected MIAPaCa2 (Fig. 3f) and AsPC1 (Fig. 3g) respectively after $24 \mathrm{~h}$ by flow cytometry.

Western blot analysis also suggested a significantly enhanced level of Fas and its ligand (FasL) in the transfected cells (Fig. 3e). Therefore, it may be envisioned that though Neu2 is a cytosolic enzyme still it can stimulate apoptosis by the extrinsic pathway involving membranebound Fas.

\section{Neu2 reduces linkage-specific sialylation on cell surface}

So far we have demonstrated presence of Neu2 on plasma membrane (Fig. 1k, m); accordingly, we checked whether it can reduce linkage-specific sialylation on the cell surface of 


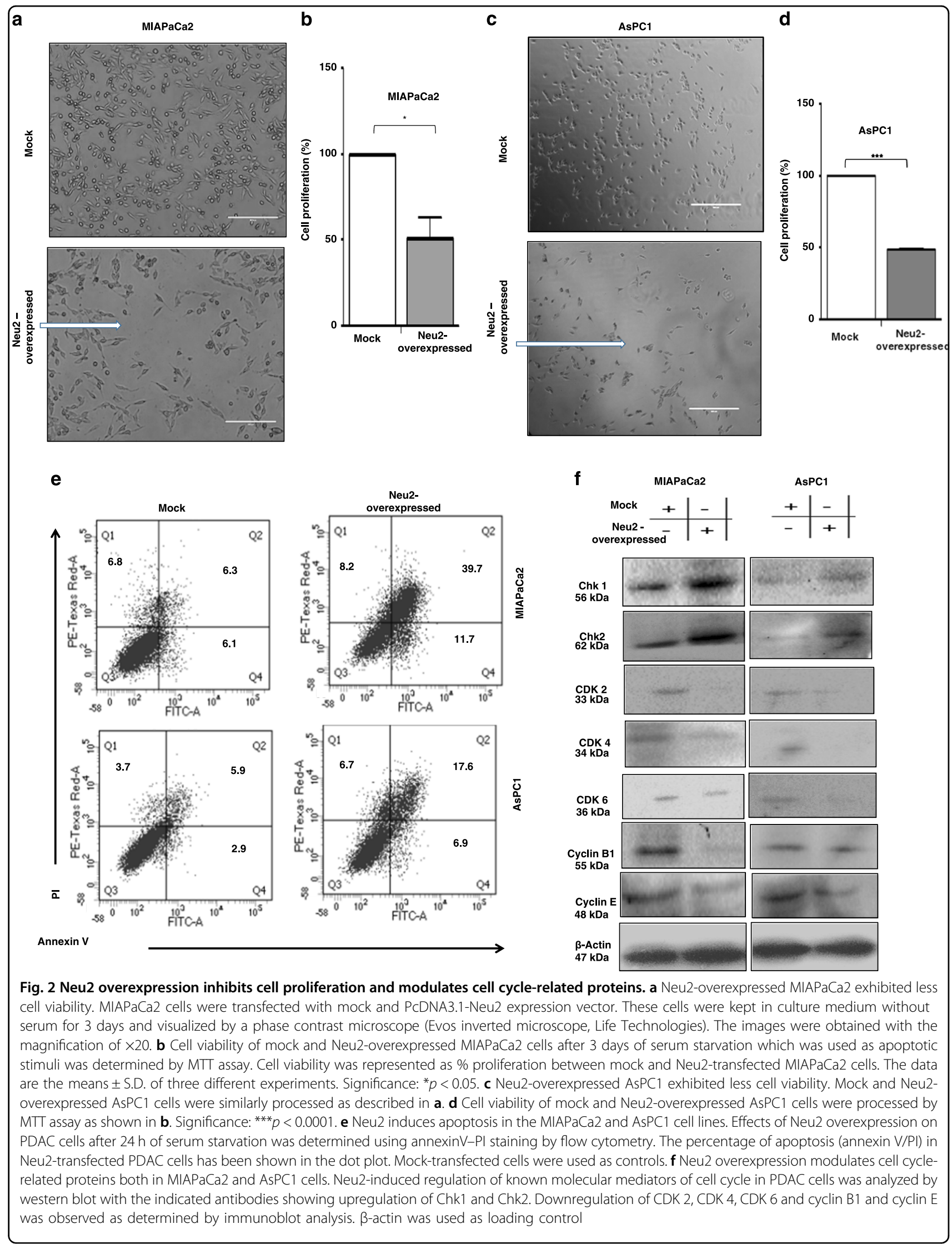




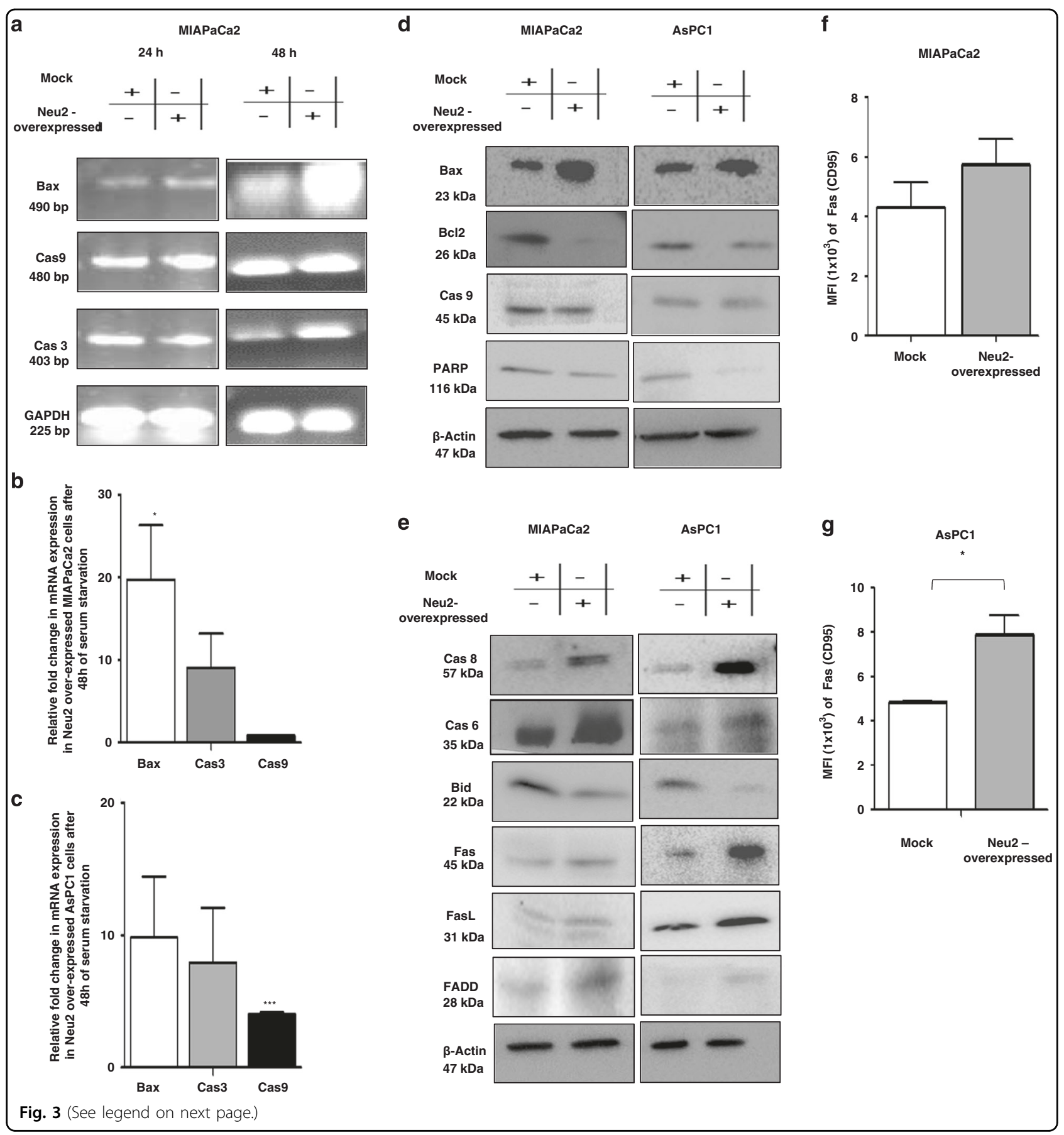

Neu2-transfected MIAPaCa2 (Fig. 4a) and AsPC1 (Fig. 4b) by flow cytometry. We have found reduced FITC-SNA binding with Neu2-overexpressed cells compared to mock as indicated by lower MFI value being $467.9 \pm 142$ vs. 607.8 \pm 144.6 in MIAPaCa2 and $228.7 \pm 32.68$ vs. $346.7 \pm 34.48$ in AsPC1 respectively. In contrast, no detectable change was found when $\alpha 2,3-$ linked SA binding lectin (MALII) was used under similar condition (data not shown). This indicates that Neu2 possibly cleaves more $\alpha 2,6$-linked SA from sialoglycoproteins on the cell surface of MIAPaCa2 and AsPC1 as $\alpha 2,6$-linked SA is reported to be the specific substrate for Neu2.

\section{Plausible association of Neu2 on plasma membrane}

As we have observed that Neu2 being a cytosolic enzyme can induce apoptosis by the extrinsic-mediated apoptotic pathway involving Fas, so we monitored whether Neu2 is also present on the membrane. Earlier, we 


\begin{abstract}
(see figure on previous page)
Fig. 3 Neu2 induces apoptosis by regulating pro and anti-apoptotic molecules. a MIAPaCa2 cells were transfected with mock and PCDNA3.1Neu2 expression vector and serum starved for 24 and $48 \mathrm{~h}$. RNA was isolated from these cells and CDNA was prepared. RT-PCR analysis of Bax, caspase 9, and casapse3 was done. mRNA expression showed upregulation of pro-apoptotic molecules but no change was found in caspase 9 in Neu2-overexpressed MIAPaCa2 cells compared to mock. GAPDH was used as loading control. The image was visualized and photographed. $\mathbf{b}$, $\mathbf{c}$ Realtime PCR analysis of Bax, caspase 3, and caspase 9 mRNA expressions in MIAPaCa2 and AsPC1 cells after Neu2 overexpression relative to that of mocktransfected cells after $48 \mathrm{~h}$ of serum starvation were determined. Values are normalized against $18 \mathrm{~S}$ rRNA expression ( $n=3$ experiments). $\mathbf{d}$ Cell lysates were prepared from mock and Neu2-overexpressed MIAPaCa2 and AsPC1 cells and resolved by SDS-PAGE, and then analyzed by western blot with the specified antibodies. Representative immunoblots showing increased Bax, reduced level of both Bcl2 and PARP in Neu2-overexpressed PDAC cells whereas no such change was found in protein level of caspase-9. $\beta$-actin was used as loading control. e Neu2 induces apoptosis through the extrinsic-mediated apoptotic pathway. Representative immunoblots of Neu2-overexpressed MIAPaCa2 and AsPC1 cells confirmed the reduction of the protein level of Bid and enhanced caspase 8, caspase 6, Fas, FasL, and FADD which are hallmark proteins of the extrinsic apoptotic pathway. $\beta$ actin was used as loading control. f MIAPaCa2 cells were transfected with mock and PcDNA3.1-Neu2 expression vector then cells were harvested and incubated with PE-Fas (CD95) antibody for analysis by flow cytometry. Neu2 overexpressed in MIAPaCa2 cells showed upregulation of Fas. The data are the means \pm S.D. of three different experiments. $\mathbf{g}$ Neu2-overexpressed AsPC1 cells also exhibited enhanced Fas on the cell surface compared to mock-transfected cells. The data are the means \pm S.D. of three different experiments. Significance: ${ }^{*} p<0.05$
\end{abstract}

have an indication of slightly higher enzyme activity on the membrane of Neu2-transfected MIAPaCa2 (Fig. 1k) and AsPC1 (Fig. 1m) along with less sialylation (Fig. 4a, b).

Now the membrane fractions of these cells were immunoblotted with an anti-Neu2 antibody. We found that higher expression of Neu2 in the membrane of the Neu2 overexpressed MIAPaCa2 (Fig. 4c) and AsPC1 (Fig. 4d). E-cadherin was used to show the purification of membrane fraction. Hence, it may be stated that Neu2 is available on the membrane by an unknown mechanism.

\section{Neu2 is associated with Fas death receptor}

So far we have established the involvement of Fas in mediating apoptosis in Neu2-overexpressed cells through extrinsic pathway. Now, we addressed an obvious question what is the relation between membrane-bound Neu2 and Fas. A co-immunoprecipitation with cell lysate (Fig. 4e) and membrane fractions (Fig. 4f) of Neu2overexpressed MIAPaCa2 and AsPC1 showed that Neu2 is associated with Fas. Higher expression of membranebound Neu2 showed more association with the death receptor suggesting possible enhanced desialylation of Fas.

\section{Neu2 causes desialylation of a2,6-linked SAs on Fas}

Fas is known to have $\alpha 2,6$-linked SAs. Therefore, we checked if the Fas is a direct target for desialylation of $\alpha 2,6$-linked SAs by Neu2. A co-immunoprecipitation with cell lysate of Neu2-overexpressed MIAPaCa2 (Fig. 4g) and AsPC1 (Fig. 4h) with anti-Fas antibody and detected by SNA exhibited decreased $\alpha 2,6$-linked SAs on Fas. The band corresponding to Fas was less intense indicating that Neu2 overexpression causes its de-sialylation. This showed that $\alpha 2,6$-linked SAs are also present on Fas in PDAC and further reconfirms that they are the true substrate for Neu2.
Neu2 mediates alterations in the sialoglycoprotein profile

To identify a possible molecular link between Neu2 overexpression and its association with Fas, we examined the status of sialoglycoproteins on membrane and cytosolic proteins of transfected cells using SNA and MALII lectins.

SNA-binding membrane proteins showed significant differences between Neu2-transfected MIAPaCa2 compared to mock-transfected cells (Fig. 5a). The major pattern changes occurred between 20 and $75 \mathrm{kDa}$ proteins which underwent a marked loss of SA indicating these sialoglycoproteins as the possible targets for Neu2. Ponceau $\mathrm{S}$ stained blot was used to indicate equal loading. Conversely, the appearance of Neu2 transfection in MIAPaCa2 caused only slight changes in the pattern of $\alpha 2,3$-linked sialoglycoproteins.

Similar changes in the reduction of 20 and $100 \mathrm{kDa}$ sialoglycoproteins profiles were observed in cytosolic proteins of transfected MIAPaCa2 (Fig. 5b). It may be noted that most of the molecules in the PI3K-signaling pathway are between 15 and $100 \mathrm{kDa}$ and they are modulated by their sialylation status. Therefore, enhanced cytosolic Neu2 possibly has a direct role in regulating some signaling pathway by desialylation. Therefore, our observation may provide a possible link between Neu2 activity and alterations of growth factormediated signaling due to desialylation by Neu2 overexpression.

\section{Neu2 impairs the activity of several signaling molecules involved in PI3K-Akt/mTOR pathway}

PI3K is known to play a key role in Akt-mTOR signaling and help cancer cells to survive. So far we have demonstrated the association of $\alpha 2,6$-linked sialylated Fas with membrane-bound Neu2 and its activation through desialylation (Fig. 4g, h). Additionally, enhanced cytosolic Neu2 may have a direct effect on regulating PI3K pathway 


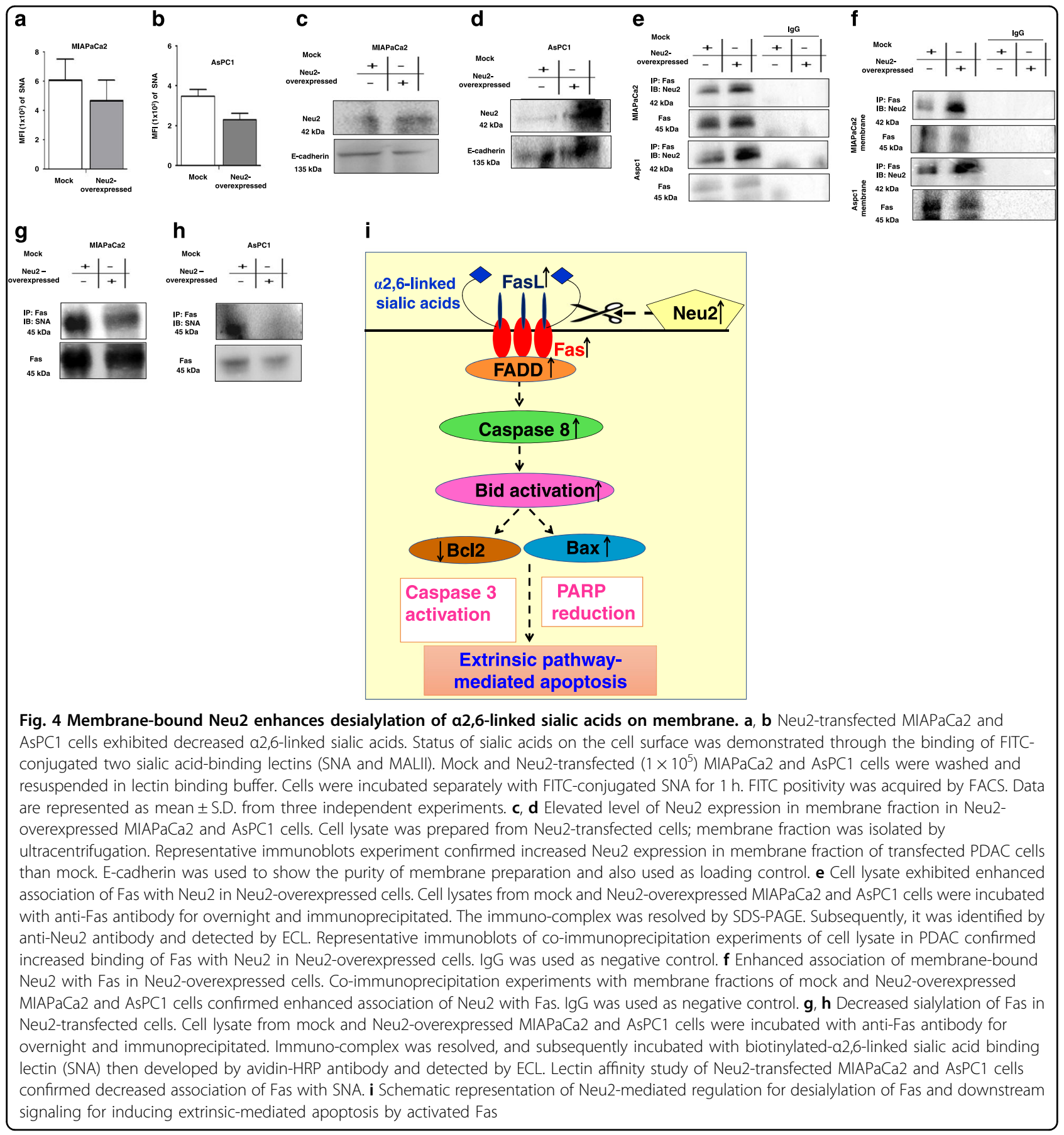

probably by modulation of sialylation of several molecules involved in this pathway. Inhibition of PI3K pathway causes upregulation of Fas which had been reported ${ }^{42}$. However, cross talk between enhanced Neu2, inhibition of the PI3K pathway, and Fas activation has not been explored.

Therefore, we turned our attention to the upstream proteins of this pathway involved in uncontrolled proliferation. We observed a decreased level of PI3K in Neu2-transfected
MIAPaCa2 and AsPC1 (Fig. 5c). Neu2 overexpression inhibited PDK1 phosphorylation at Ser241. Thus this sialidase possibly reduces the PDK1-mediated Akt/mTOR signaling. PDK1 partially activates Akt phosphorylation at Thr308, we have also found decreased phosphorylation in Neu2-overexpressed cells.

Furthermore, to check the effect in the intracellular phases of signaling, we evaluated specific phosphorylation level of mTOR complexes and its downstream signaling 
proteins in Neu2-transfected MIAPaCa2 and AsPC1 (Fig. 5d). They exhibited reduced phosphorylation at Ser2481 indicating mTORC2-specific phosphorylation. We examined the phosphorylation status of AKT at Ser473, which is a selective substrate of mTORC2 for confirming this upstream inhibition of mTORC2 signaling in these Neu2-transfected cells. We observed reduced expression of phospho-AKT at Ser473 (Fig. 5c). This observation strongly suggested that Neu2 overexpression had a significant role in the reduction of mTORC2 activity, which in turn decreased the phosphorylation of its substrate AKT at the Ser473.

We also detected slightly reduced levels of phosphorylation of active mTORC1 at Ser 2448 in Neu2- transfected MIAPaCa2 and AsPC1 (Fig. 5d). As PDK1 pathway regulates mTORC1 activity which consequently controls the downstream signaling molecules, therefore, we studied the phosphorylation of S6K1 and 4E-BP1. We observed reduced phosphorylation of S6K1 at Thr389, 4EBP1 at Thr37/46, and GSK3 $\beta$ after overexpression of Neu2 in these cells suggesting the involvement of mTORC1 also. Taken together, all these observations suggest that overexpression of Neu2 causes reduction of growth factor-mediated several signaling molecules in the PI3K pathway, as a whole through modulation of sialylation which also could activate Fas. Thus, the activated Fas possibly deregulates the overall pathways for cell proliferation.

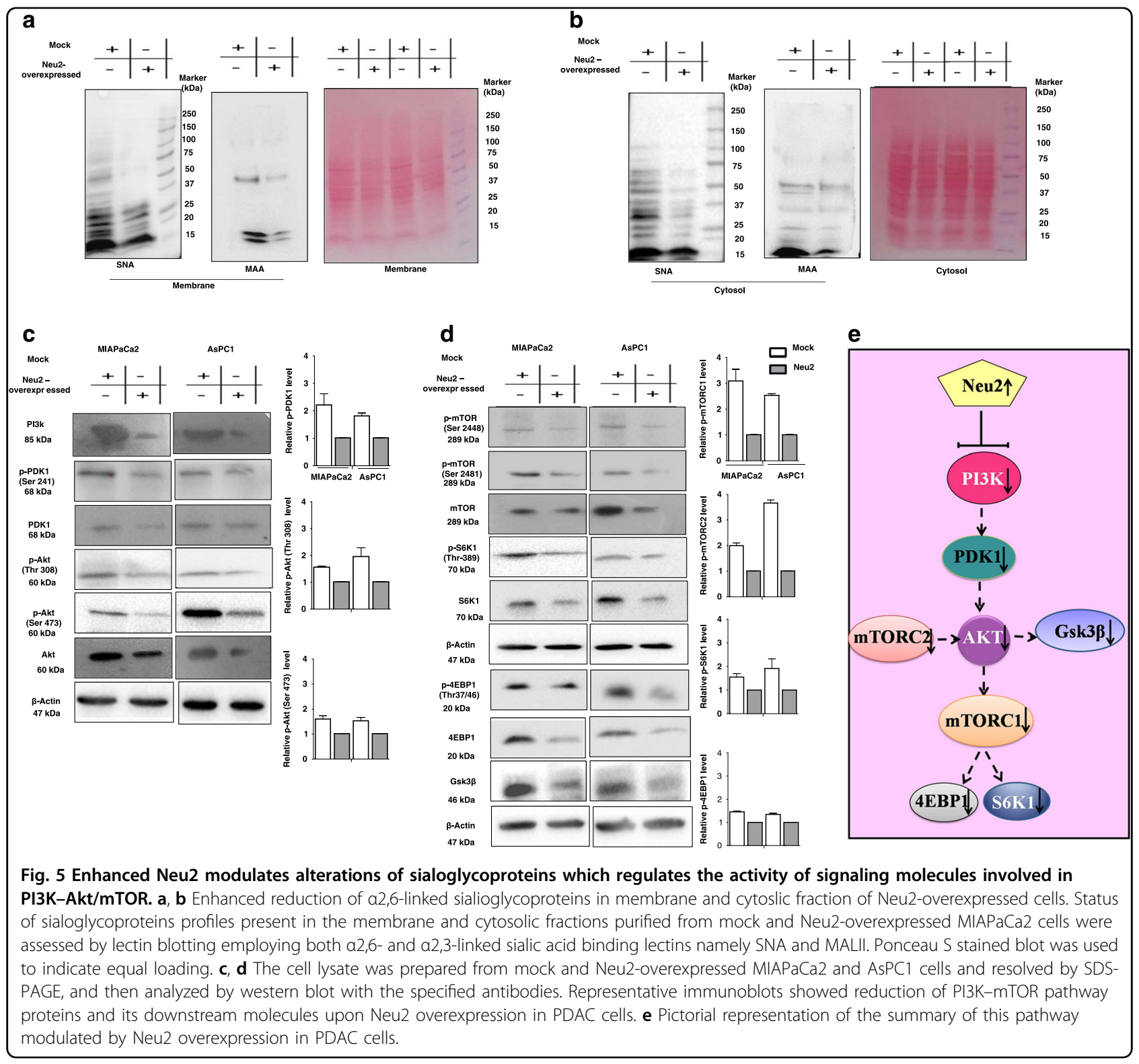




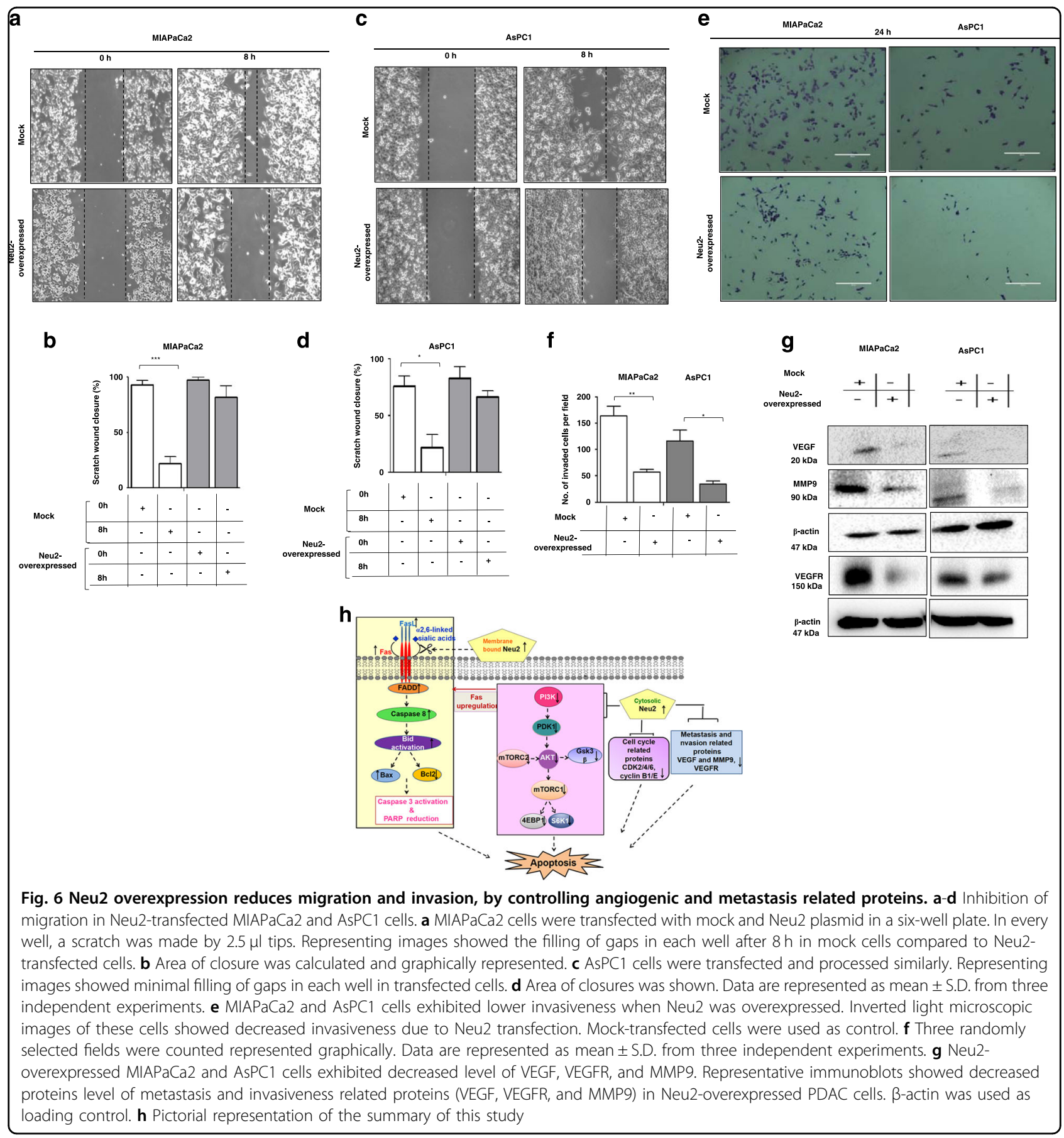

\section{Enhanced Neu2 reduces cell migration and invasion} through the modulation of VEGF, VEGFR, and MMP9

Next, we checked the role of enhanced Neu2 in metastasis through migration and invasion assays. We observed there was no significant change in cell migration of Neu2-overexpressed MIAPaCa2 (Fig. 6a, b) and AsPC1 (Fig. 6c, d) after $8 \mathrm{~h}$ by scratch wound assay (Table 3 ) compared to mock.
Additionally, we investigated the potential ability for invasiveness of Neu2-overexpressed cells. Mock-transfected MIAPaCa2 and AsPC1 invade Matrigel layer after $24 \mathrm{~h}$ (Fig. 6e). However, not much invasion of Neu2-transfected cells was observed. The number of invaded cells per-field in mock was much higher than Neu2-transfected cells (Fig. 6f). Taken together, Neu2transfected cells possess less invasive property (Table 3 ). 
Table 3 Values of migration and invasion assay in MIAPaCa2 and AsPC1 cells

\begin{tabular}{|c|c|c|c|c|}
\hline \multirow[t]{2}{*}{ Migration assay } & \multicolumn{2}{|c|}{ MIAPaCa2 scratch wound closure (\%) } & \multicolumn{2}{|c|}{ AsPC1 scratch wound closure (\%) } \\
\hline & $\mathrm{Oh}$ & $8 \mathrm{~h}$ & $\mathrm{Oh}$ & $8 \mathrm{~h}$ \\
\hline Mock & $93.30 \pm 3.9$ & $22.22 \pm 5.9$ & $75.92 \pm 9.26$ & $22.17 \pm 11.5$ \\
\hline $\mathrm{Neu} 2$ & $97.77 \pm 2$ & $82.22 \pm 9.7$ & $83.32 \pm 9.62$ & $66.57 \pm 5.56$ \\
\hline Invasion assay & \multicolumn{2}{|c|}{ : Number of invaded cells per field } & & \\
\hline \multirow[t]{2}{*}{ Mock } & $24 \mathrm{~h}$ & $24 \mathrm{~h}$ & & \\
\hline & $163.7 \pm 18.35$ & $116.0 \pm 20.74$ & & \\
\hline Neu2 & $57.0 \pm 5.13$ & $34.67 \pm 5.55$ & & \\
\hline
\end{tabular}

To further strengthen the reduced inability of Neu2transfected cells in metastasis and invasion, we have checked the status of a few specific hallmark proteins like vascular endothelial growth factor (VEGF), vascular endothelial growth factor receptor proteins (VEGFR), and matrix metalloproteinase 9 (Fig. 6g). All these molecules were decreased compared to mock-transfected cells. Hence, it seems that not only enhanced Neu2 induces apoptosis but it can also have the potential to reduce the metastasis even in drug-resistant MIAPaCa2.

\section{Discussion}

Aberrant sialylation in signaling pathways involved in altering their functions leads to abnormal cellular signaling causing major changes in cellular behavior to induce resistance to apoptosis and invasiveness ${ }^{44}$. Sialyltransferases and sialidases are two important players in this event. The key achievement of our study is to provide evidence for the enhancement of cytosolic Neu2 on the membrane in the Neu2-overexpressed PDAC cells. We have demonstrated for the first time a close association of membrane-bound Neu2 with sialylated Fas, which plays a major regulatory upstream molecule for the activation of Fas through desialylation. Activated Fas, after desialylation, enhanced several apoptotic molecules through extrinsic apoptotic pathway caused by increased Neu2 on the membrane. Fas activation is also modulated by desialylation of several molecules involved in the PI3K pathway by enhanced cytosolic-Neu2 activity. The effect of all these was reflected in decreased metastasis, invasiveness, and cellular proliferation due to decreased PI3K-pathway activity through modulation of sialylation which helps in upregulation of Fas activation due to enhanced Neu2. Moreover, a significant strong association of lower expression status of Neu2 with clinicopathological characteristics in patient tissues has also been demonstrated.

Several reports suggested that higher sialylation status causes cell motility, adhesion, and metastasis by modulating $\alpha 2,3$ sialyltransferase, ST3GalIII, galactosyl transferases in PDAC ${ }^{25}$. ST6Gal1 also plays an important role in regulating the invasiveness in a fructose-responsive manner $^{24}$. This enzyme enhances $\alpha 2,6$-sialylation of Fas which confers protection against Fas-mediated apoptosis and facilitates tumor progression in colon cancer ${ }^{36}$. We have also shown $\alpha 2,6$-sialylation of Fas in PDAC. To the best of our knowledge, this is the first report on Fassialylation in PDAC.

Conformation changes of glycoproteins, recognition of functional molecules especially in relation to cancer progression are usually caused by removal of SAs which was catalyzed by a sialidase $\mathrm{e}^{26}$. These observations comprised the preface of our study to evaluate the effects of cytosolic-sialidase $\mathrm{Neu} 2$, which is present in very low amount in PDAC cells. The role of Neu2 in differentiation events is an extremely regulated process ${ }^{29}$. Enhanced Neu2 expression leads leukemic cells towards apoptosis ${ }^{31}$. However, several tumor cells generally with a high degree of malignancy are lacking this sialidase ${ }^{45}$.

Due to lack of adequate understanding of the mechanism by which Neu2 regulates tumor cell behavior in pancreatic carcinoma, we aimed to explain the significance of Neu2 downregulation. Accordingly, we overexpressed Neu2 in drug-resistant PDAC cells.

Neu2 overexpression showed apoptosis susceptibility toward apoptotic stimuli such as serum deprivation which significantly reduced the proliferation rate. More importantly, this event pushed Neu2-overexpressed cells toward apoptosis as revealed by an increased number of cells in the late apoptotic stage by affecting important cell cycle regulatory molecules along with increasing the expression of the pro-apoptotic and decreasing the anti-apoptotic proteins. Interestingly, caspase 6 and 8 were activated but not caspase 9 hinting for activation of the extrinsic pathway. Furthermore, we observed higher enzyme activity in the membrane fraction. This outcome gave us first notion that Neu2 probably present in the membrane in transfected cells by an unknown mechanism which desialylated $\alpha 2,6$ linked SAs of cell surface sialoglycoproteins. Interestingly, $\alpha 2,6$-linked SAs are considered to be the main substrate for 
Neu2 in pancreatic cancer. This was corroborated by the significant differences in sialylation profile of various sialoglycoproteins both in membrane and cytosol between mock and Neu2-transfected cells suggesting desialylation may be the cause of the effects which was activated by Neu2. Changes were more prominent in cleaving $\alpha 2,6-$ linked sialoglycoproteins. No appreciable changes in the level of $\alpha 2,3$-linked SAs were observed.

The activation of the Fas-apoptotic pathway by the inhibition of the PI3K/Akt pathway was reported in colon cancer $^{42}$. It was also found that inhibition of PI3K pathway causes Fas activation in gastric cancer and in prostate cancer ${ }^{41,43}$. Thus, considerable efforts have been made for understanding the molecular crosstalk between PI3K and Fas-mediated cell death in PDAC cells. All these events have been demonstrated pictorially in Fig. $6 \mathrm{~h}$.

Taken together, to the best of our knowledge, this is the first evidence demonstrating cytosolic Neu2 on the membrane which plays as an upstream important molecule for establishing a cross-talk between Neu2, activation of Fas, induction of extrinsic pathway and inhibition of PI3K pathway to induce apoptosis in drug-resistant human pancreatic cancer cells.

\section{Material and methods Chemicals}

2 '-(4-Methylumbelliferyl)- $\alpha$-D- $N$-acetylneuraminic acid (4MU-NeuAc), 4-methylumbelliferone (MU) and MTT were from Sigma (St. Louis, USA). Anti-Neu1/Neu3 (Invitrogen)/ Neu2 (Abnova, Taiwan)/Neu4 (Pierce), PE-Fas (CD95, BD Bioscience, USA) antibodies and all other antibodies were from Cell Signalling Technology (Danvers, USA). PcDNA3.1-Neu2 was the kind gift from Dr. Eugenio Monti.

\section{Patient samples}

The surgical specimens were obtained from pancreatic cancer patients who underwent resection of their tumors from Institute of Postgraduate Medical Education and Research Hospital, Kolkata. The Institutional Human Ethical Committee had approved the study. Consent of the patients or their parents/guardians were taken for the sample needed for this study. All the clinicopathological details of patients included in this study are summarized in Table 1.

\section{Immunohistochemistry}

For immunohistological staining, pancreatic tumors and adjacentnormal tissues were fixed, embedded in paraffin and microtome-sectioned. To assess the expression of all four sialidases (Neu1/Neu2/Neu3/Neu4), the sections were heated in $0.01 \mathrm{M}$ citrate buffer $(\mathrm{pH}$ 6.0) for recovery of antigen and incubated with the respective antibodies. The tissue samples were photographed at $\times 20$ magnification and IHC optical density score was measured by ImageJ software. All 40 samples were used for IHC of
Neu2, whereas 10 samples were evaluated for Neu1, Neu3, and Neu4.

\section{Cell culture}

MIAPaCa2, AsPC1, BxPC3, and PANC1 were purchased from ATCC (Table 2). MIAPaCa2, AsPC1, and BxPC3 cells were cultured in RPMI-1640 medium, and PANC1 was cultured in IMDM medium supplemented with heat-inactivated FCS $[10 \%(\mathrm{v} / \mathrm{v})]$, L-glutamine $(0.002$ $\mathrm{M})$, antibiotics, and antimycotics (Medium A). STR profiling of MIAPaCa2 and AsPC1 was done at University of Nebraska Medical Center, USA.

\section{Detection of genetic expression of sialidases}

Total RNA from cells was extracted using RNeasy mini kit following the manufacturer's instruction. First strand cDNA was synthesized by ImPromII-Reverse transcription system according to manufacturer's protocol.

Semi-quantitative RT-PCR was performed on PTC-100 (MJ Research, GMI Ramsey, MN) using PCR kit with specific primers (Table 4). Expression of GAPDH was used as a housekeeping gene. Real-time PCR was performed using a DyNAmo Flash SYBR Green qPCR Kit. Relative amounts of target mRNA were quantitated using the LightCycler 96 (Roche) software with 18S rRNA as internal control. Neu2 level was also detected by western blot analysis using anti-Neu2 antibody.

\section{Transfection of PcDNA3.1-Neu2 into pancreatic cancer cells}

MIAPaCa2 and AsPC1 cells $\left(1 \times 10^{6} /\right.$ well $)$ in Medium $A$ at $80 \%$ confluence were transfected with Neu2 cDNA inserted into the pcDNA3.1 expression vector by the transfection reagent, lipofectamine-ltx according to the manufacturer's instructions in a six-well plate. The transfection mixture was removed next day and replaced with fresh medium. Mock transfection was used as the control in all the experiments.

\section{Sialidase assay}

Neu2-transfected cells were cultured for $48 \mathrm{~h}$, resuspended in phosphate-buffered saline (PBS), containing pepstatin A $(1.0 \mu \mathrm{g} / \mathrm{ml})$, aprotinin $(10 \mu \mathrm{g} / \mathrm{ml})$, and leupeptin $(10 \mu \mathrm{g} / \mathrm{ml})$. The cells were lysed by sonication (Qsonica-LLC, XL-2000 series, Newtown, CT, USA) and centrifuged at $800 \times g$ for $10 \mathrm{~min}$. The supernatant was further centrifuged at $1,000,00 \times g$ for $30 \mathrm{~min}$ to separate cytosolic and membrane fractions. The sialidase activity in cytosol $(50 \mu \mathrm{g})$ and membrane $(100 \mu \mathrm{g})$ was determined by using a fluorimetric assay with 4-MU-Neu5Ac (400 $\mu \mathrm{M})$ as a substrate. The reaction mixture was incubated at $37^{\circ} \mathrm{C}$ for $1 \mathrm{~h}$ in sodium acetate buffer $(50 \mathrm{mM}, \mathrm{pH} 5.5)$. Enzymatic activity was expressed as $\mu \mathrm{M}$ of product per $\mathrm{h} /$ mg protein. 
Table 4 List of primers

\begin{tabular}{lll}
\hline & Forward primer & Reverse primer \\
\hline Neu1 & 5'-CCTGGATATTGGCACTGAA-3' & 5'-CATCGCTGAGGAGACAGAAG-3' \\
Neu2 & 5'-AGAAGGATGAGCACGCAGA-3' & 5'-GGATGGCAATGAAGAAGAGG-3' \\
Neu3 & 5'-TGAGGATTGGGCAGTTGG-3' & 5'-CCCGCACACAGATGAAGAA-3' \\
Neu4 & 5'-TCACTCCTTCGCCTTCTA-3' & 5'-GGCATTGCAGTAGAGGAA-3' \\
Bax & 5'-GGGGACGAACTGGACAGTAA-3' & 5'-CCTCCCAGAAAAATGCCATA-3' \\
Cas3 & 5'-TGGAATTGATGCGTGATGTT-3' & 5'-TCAAGCTTGTCGGCATACTG-3' \\
Cas9 & 5'-GTGCTGAACATCCCACAATG-3' \\
GAPDH & 5'-GCTTAGGGTCGCTAATGCTG-3' \\
\hline
\end{tabular}

\section{Cell viability assay}

Mock and Neu2-transfected cells $\left(1 \times 10^{4} / 100 \mu \mathrm{l}\right)$ were seeded in 96-well culture plates under serum-depletion conditions for $72 \mathrm{~h}$ and subsequently incubated with MTT $(100 \mu \mathrm{g} / \mathrm{ml})$ for $3 \mathrm{~h}$. Formazan crystals were dissolved in DMSO and OD was taken at $550 \mathrm{~nm}$ in an ELISA reader (Thermo Scientific, USA). In parallel, the viability of the cells was also monitored by inverted microscopy and the microscopic images were captured after $72 \mathrm{~h}$.

\section{Annexin V-PI positivity}

Mock and Neu2-transfected cells $\left(1 \times 10^{6}\right)$ were cultured in absence of serum for $24 \mathrm{~h}$. Cells were suspended in annexin $\mathrm{V}$-binding buffer incubated for $45 \mathrm{~min}$ in dark at $25^{\circ} \mathrm{C}$. AnnexinV and PI were added according to the manufacturer's instruction and incubated for $20 \mathrm{~min}$ in dark at $4{ }^{\circ} \mathrm{C}$. Acquisition of annexin V and PI positive cells were analyzed by flow cytometry (FACS) (BD LSRFORTESSA) using BD FACSDiva 8.0 software.

\section{Apoptosis detection assays}

Mock and Neu2-transfected cells $\left(1 \times 10^{6}\right)$ to apoptotic stimuli was evaluated by culturing cells under serumdepletion conditions for $48 \mathrm{~h}$. Different types of caspases and pro-apoptotic molecules both in genes and proteins levels were detected by RT-PCR and qRT-PCR, western blotting using specific primers (Table 4 ), and respective antibodies.

\section{Detection of Fas (CD95)}

Neu2 and mock-transfected cells $\left(5 \times 10^{5}\right)$ were washed, resuspended in PBS $(100 \mu \mathrm{l})$, and incubated with PE-conjugated anti-Fas (CD95) antibody for $30 \mathrm{~min}$ in the dark and subsequently acquired by FACS.

\section{Detection of linkage-specific SAs through lectin binding by FACS}

Presence of linkage-specific SAs in MIAPaCa2 and AsPC1 cells was explored by using two sialic acid- binding lectins namely SNA and Maackia amurensis agglutinin (MALII). Mock and Neu2-transfected $(1 \times$ $10^{5}$ ) cells were washed and resuspended in lectin binding buffer (20 mM Tris, $0.5 \mathrm{M} \mathrm{NaCl}, 2.0 \mathrm{mM} \mathrm{MnCl}_{2}, 2.0$ $\mathrm{mM} \mathrm{MgCl}_{2}, 2.0 \mathrm{mM} \mathrm{CaCl}_{2}$ ). Cells were incubated separately with FITC-conjugated SNA and MALII for 1 h $\left(5.0 \mu \mathrm{g} / \mathrm{ml}\right.$ at $\left.4{ }^{\circ} \mathrm{C}\right)$, and FITC positivity was acquired by FACS.

\section{Co-immunoprecipitation}

For detection of the association of Fas with Neu2, mock and Neu2-transfected PDAC cells were lysed. Total cell lysate protein $(200 \mu \mathrm{g})$ was incubated with the anti-Fas antibody $(1: 100)$ overnight at $4{ }^{\circ} \mathrm{C}$. Immunocomplex was incubated with protein A-Sepharose $4 \mathrm{~B}$ for $3 \mathrm{~h}$, resolved by SDS-PAGE, and subsequently identified using the anti-Neu2 antibodies. Membrane fraction of mock and Neu2-transfected MIAPaCa2 and AsPC1 cells was similarly processed ${ }^{46}$. Rabbit IgG was used as a negative control.

\section{Detection of sialoglycoproteins on Fas by co- immunoprecipitation with SNA}

To detect the status of $\alpha 2,6$-linked sialic acids on Fas in Neu2-overexpressed MIAPaCa2 and AsPC1, cell lysate was incubated with the anti-Fas antibody (1:100) overnight at $4{ }^{\circ} \mathrm{C}$. Immuno-complex was incubated with protein A-Sepharose $4 \mathrm{~B}$ for $3 \mathrm{~h}$, resolved by SDS-PAGE, and subsequently detected by using the biotinylated SNA and developed with avidin-HRP. Mock-transfected cells were processed similarly for comparison.

\section{Glycoprotein analysis}

Proteins $(100 \mu \mathrm{g})$ isolated from the membrane and cytosolic fractions of mock and Neu2-transfected MIA$\mathrm{PaCa} 2$ cells were separated on (4-20\%) gradient SDSPAGE and transferred onto a PVDF membrane. $\alpha 2,6-$ and $\alpha 2,3$-linked SAs were identified by incubating with 
biotinylated SNA and MALII separately and subsequently developed with avidin-HRP. Ponceau S stained blot was used to indicate equal loading.

\section{Migration assay}

Mock and Neu2-transfected MIAPaCa2 and AsPC1 cells $\left(1 \times 10^{6}\right)$ were cultured to $>80 \%$ confluency in a six-well plate. Three separate scratch wounds were made and incubated for $24 \mathrm{~h}$. Number of cells that moved into

the scratched area was observed, and images were taken by using phase contrast microscopy (EVOS, Life Technologies).

\section{Invasion assay}

Mock and Neu2-overexpressed MIAPaCa2 and AsPC1 cells $\left(2.5 \times 10^{4}\right)$ were suspended in medium (100 $\mu \mathrm{l})$ without FBS and added to the upper chamber of the insert ( $6.5 \mathrm{~mm}$ diameter, $8 \mu \mathrm{m}$ pore size; Becton Dickson). Then, it was placed in a 24-well plate with medium and $10 \%$ FBS $(900 \mu \mathrm{l})$. After $24 \mathrm{~h}$, the invaded cells were fixed with $3.7 \%$ formaldehyde and stained with crystal violet solution. Cells on the upper side of the insert were removed by a cotton swab. Three randomly selected fields on the lower side of the insert were photographed, and the migrated cells were counted.

\section{Statistical analysis}

All the data were from three independent experiments and statistical analysis was performed using Graph Pad Prism 5. Two tail Student's $t$ test was used to detect the differences between the groups. Standard error bars represent the standard deviation of the mean $( \pm$ S.D. $)$ and $" p<0.05$ represented the significant differences between the means of the two test groups.

\section{Acknowledgements}

S.N. is an SRF of University grant commission (UGC). We sincerely acknowledge Eugenio Monti, Department of Molecular and Translational Medicine, University of Brescia, Italy for providing PcDNA3.1-Neu2 plasmid, Dr. Kaustubh Dutta, Department of Biochemistry and Molecular biology, University of Nebraska Medical Center, USA for STR profiling, Mr. Asish Mallick and Rita Maity for their technical help, Samarpan Maiti and Chandan Mandal for fruitful discussion. Director (CSIR-IICB) is kindly acknowledged for providing all institutional facilities. This study is supported by CSIR (ESC0103), Department of Biotechnology (DBT, GAP 346), Department of Science and Technology (DST, GAP 336/GAP 339), Govt. of India. CM is grateful for financial support by Sir J.C. Bose National Fellowship, DST, Govt. of India and DBT-Distinguished Biotechnology Research professorship award.

\footnotetext{
Author details

${ }^{1}$ Cancer Biology and Inflammatory Disorder Division, Council of Scientific and Industrial Research (CSIR), Indian Institute of Chemical Biology (IICB), 4, Raja S.C. Mullick Road, Jadavpur, Kolkata 700032 West Bengal, India. ${ }^{2}$ National Institute of Pharmaceutical Education and Research, IICB, CSIR, Kolkata 700032 West Bengal, India. ${ }^{3}$ Department of Pathology, Institute of Postgraduate Medical Education and Research, Institute of Post-Graduate Medical Education and Research Hospital, Kolkata 700020 West Bengal, India
}

\section{Authors' contributions}

Conceived and designed the experiments: S.N. and Chi.M. Performed the experiments: S.N. Enzymatic analysis: Chh.M. Immunohistochemistry: Biobanking and patient consent, surgical specimen collection, processing and image analysis: U.C. Analyzed the data: S.N., Chh.M., and Chi.M. Wrote the paper: S.N., Chh.M., and Chi.M. Corrected in the present format: Chi.M.

\section{Conflict of interest}

The authors declare that they have no conflict of interest.

\section{Publisher's note}

Springer Nature remains neutral with regard to jurisdictional claims in published maps and institutional affiliations.

Received: 4 October 2017 Revised: 29 November 2017 Accepted: 30 November 2017

Published online: 12 February 2018

\section{References}

1. Muders, M. H. et al. Expression and regulatory role of GAIP-interacting protein GIPC in pancreatic adenocarcinoma. Cancer Res. 66, 10264-10268 (2006).

2. Muders, M. H. et al. Targeting GIPC/Synectin in pancreatic cancer inhibits tumor growth. Clin. Cancer 15, 4095-4103 (2009).

3. Wang, Z. et al. Targeting notch to eradicate pancreatic cancer stem cells for cancer therapy. Anticancer Res. 31, 1105-1113 (2011).

4. Sarkar, S. et al. Oxidative inhibition of Hsp90 disrupts the super-chaperone complex and attenuates pancreatic adenocarcinoma in vitro and in vivo. Int. J. Cancer 132, 695-706 (2013).

5. Sarkar, S., Mandal, C., Sangwan, R. \& Mandal, C. Coupling G2/M arrest to the Wnt/ $\beta$-catenin pathway restrains pancreatic adenocarcinoma. Endocr. Relat. Cancer 21, 113-125 (2014)

6. Mandal, C., Sarkar, S., Chatterjee, U., Schwartz-Albiez, R. \& Mandal, C. Disialoganglioside GD3-synthase over expression inhibits survival and angiogenesis of pancreatic cancer cells through cell cycle arrest at S-phase and disruption of integrin- $\beta 1$-mediated anchorage. Int. J. Biochem. Cell Biol. 53, 162-173 (2014).

7. Mandal, C., Chatterjee, M. \& Sinha, D. Investigation of 9-O-acetylated sialoglycoconjugates in childhood acute lymphoblastic leukaemia. Br. J. Haematol. 110, 801-812 (2000).

8. Chowdhury, S. \& Mandal, C. O-acetylated sialic acids: multifaceted role in childhood acute lymphoblastic leukaemia. Biotechnol. J. 4, 361-374 (2009).

9. Pal, S. et al. Differential expression of 9-O-acetylated sialoglycoconjugates on leukemic blasts: a potential tool for long-term monitoring of children with acute lymphoblastic leukemia. Int. J. Cancer 111, 270-277 (2004).

10. Narayanan, S. Sialic acid as a tumor marker. Ann. Clin. Lab. Sci. 24, 376-384 (1994).

11. Büll, C., Stoel, M. A., den Brok, M. H. \& Adema, G. J. Sialic acids sweeten a tumor's life. Cancer Res. 74, 3199-3204 (2014).

12. Pearce, O. M. \& Läubli, H. Sialic acids in cancer biology and immunity. Glycobiology 26, 111-128 (2016).

13. Ulloa, F. \& Real, F. X. Differential distribution of sialic acid in a2, 3 and a2, 6 linkages in the apical membrane of cultured epithelial cells and tissues. J. Histochem. Cytochem. 49, 501-509 (2001).

14. Bassagañas, S., Pérez-Garay, M. \& Peracaula, R. Cell surface sialic acid modulates extracellular matrix adhesion and migration in pancreatic adenocarcinoma cells. Pancreas 43, 109-117 (2014).

15. Monti, E. et al. Sialidases in vertebrates. A family of enzymes tailored for several cell functions. Adv. Carbohydr. Chem. Biochem. 64, 403-479 (2010).

16. Mandal, C. Regulation of O-acetylation of sialic acids by sialate-Oacetyltransferase and sialate-O-acetylesterase activities in childhood acute lymphoblastic leukemia. Glycobiology 22, 70-83 (2012).

17. Mondal, S., Chandra, S. \& Mandal, C. Elevated mRNA level of hST6Gal I and hST3Gal V positively correlates with the high risk of pediatric acute leukemia. Leuk. Res. 34, 463-470 (2010).

18. Mandal, C. et al. High level of sialate-O-acetyltransferase activity in lymphoblasts of childhood acute lymphoblastic leukaemia (ALL): enzyme characterization and correlation with disease status. Glycoconj. J. 26, 57-73 (2009). 
19. Glavey, S. V. et al. The sialyltransferase ST3GAL6 influences homing and survival in multiple myeloma. Blood 124, 1765-1776 (2014)

20. Harvey, B. E. et al. Sialyltransferase activity and hepatic tumor growth in a nude mouse model of colorectal cancer metastases. Cancer Res. 52, 1775-1779 (1992).

21. Zhao, Y. et al. a2,6-Sialylation mediates hepatocellular carcinoma growth in vitro and in vivo by targeting the Wnt/ $\beta$-catenin pathway. Oncogenesis $\mathbf{6}$, e343 (2017)

22. Cao, Y., Merling, A., Crocker, P. R., Keller, R. \& Schwartz-Albiez, R. Differential expression of beta-galactosidealpha2,6 sialyltransferase and sialoglycans in normal and cirrhotic liver and hepatocellular carcinoma. Lab. Invest. 82, 1515-1524 (2002)

23. Bassagañas, S. et al. Pancreatic cancer cell glycosylation regulates cell adhesion and invasion through the modulation of a $2 \beta 1$ integrin and E-cadherin function. PLOS ONE 9, e98595 (2014).

24. Hsieh, C.-C. et al. Elevation of $\beta$-galactoside $a 2$, 6-sialyltransferase 1 in a fructose- responsive manner promotes pancreatic cancer metastasis. Oncotarget 8, 7691-7709 (2016)

25. Pérez-Garay, M. et al. a2,3-Sialyltransferase ST3Gal IV promotes migration and metastasis in pancreatic adenocarcinoma cells and tends to be highly expressed in pancreatic adenocarcinoma tissues. Int. J. Biochem. Cell Biol. $\mathbf{4 5}$ 1748-1757 (2013)

26. Miyagi, T. Aberrant expression of sialidase and cancer progression. Proc. Jpn. Acad. Ser. B Phys. Biol. Sci. 84, 407-418 (2008).

27. Mandal, C. et al. Down regulation of membrane-bound Neu3 constitutes a new potential marker for childhood acute lymphoblastic leukemia and induces apoptosis suppression of neoplastic cells. Int. J. Cancer 126, 337-349 (2010).

28. Koseki, K. et al. Human cytosolic sialidase NEU2-low general tissue expression but involvement in PC-3 prostate cancer cell survival. Biochem. Biophys. Res. Commun. 428, 142-149 (2012).

29. Fanzani, A., Colombo, F., Giuliani, R., Preti, A. \& Marchesini, S. Cytosolic sialidase Neu2 upregulation during PC12 cells differentiation. FEBS Lett. 566, 178-182 (2004).

30. Fanzani, A. et al. Overexpression of cytosolic sialidase Neu2 induces myoblast differentiation in C2C12 cells. FEBS Lett. 547, 183-188 (2003).

31. Tringali, $C$. et al. Expression of sialidase Neu2 in leukemic $\mathrm{K} 562$ cells induces apoptosis by impairing Bcr-Abl/Src kinases signaling. J. Biol. Chem. 282 14364-14372 (2007)
32. Tokuyama, S. et al. Suppression of pulmonary metastasis in murine B16 melanoma cells by transfection of a sialidase cDNA. Int. J. Cancer 73, 410-415 (1997).

33. Sawada, M. et al. Reduced sialidase expression in highly metastatic variants of mouse colon adenocarcinoma 26 and retardation of their metastatic ability by sialidase overexpression. Int. J. Cancer 97, 180-185 (2002).

34. Von Reyher, U. et al. Colon carcinoma cells use different mechanisms to escape CD95-mediated apoptosis. Cancer Res. 58, 526-534 (1998).

35. Keane, M. M. et al. Fas expression and function in normal and malignant breast cell lines. Cancer Res. 56, 4791-4798 (1996).

36. Swindall, A. F. \& Bellis, S. L. Sialylation of the Fas death receptor by ST6Galprovides protection against Fas-mediated apoptosis in colon carcinoma cells. J. Biol. Chem. 286, 22982-22990 (2011).

37. Sadeghi, N. \& GerberD., E. Targeting the PI3K pathway for cancer therapy. Future Med. Chem. 4, 1153-1169 (2012).

38. Morgensztern, D. \& McLeod, H. L. PI3K/Akt/mTOR pathway as a target for cancer therapy. Anticancer Drugs 16, 797-803 (2005).

39. Zhao, Y. et al. Modification of sialylation mediates the invasive properties and chemosensitivity of human hepatocellular carcinoma. Mol. Cell. Proteom. 13, 520-536 (2014).

40. Ma, $\mathrm{H}$. et al. Modification of sialylation is associated with multidrug resistance in human acute myeloid leukemia. Oncogene 34, 1-15 (2014).

41. Osaki, M. et al. Inhibition of the PI3K-Akt signaling pathway enhances the sensitivity of Fas-mediated apoptosis in human gastric carcinoma cell line, MKN-45. J. Cancer Res. Clin. Oncol. 130, 8-14 (2004).

42. Zhu, L. et al. Synergism of PI3K/Akt inhibition and Fas activation on colon cancer cell death. Cancer Lett. 354, 355-364 (2014).

43. Bertram, J. et al. Inhibition of the phosphatidylinositol 3'-kinase pathway promotes autocrine Fas-induced death of phosphatase and tensin homologue-deficient prostate cancer cells. Cancer Res. 66, 4781-4788 (2006).

44. Häuselmann, I. \& Borsig, L. Altered tumor-cell glycosylation promotes metastasis. Front. Oncol. 4, 28 (2014).

45. Miyagi, T., Takahashi, K., Hata, K., Shiozaki, K. \& Yamaguchi, K. Sialidase significance for cancer progression. Glycoconj. J. 29, 567-577 (2012).

46. Bhattacharya, K. Maiti, S. \& Mandal, C. PTEN negatively regulates mTORC2 formation and signaling in grade IV glioma via Rictor hyperphosphorylation at Thr1135 and direct the mode of action of an mTORC1/2 inhibitor. Oncogenesis 5, e227 (2016). 